\title{
SENSITIVITY ANALYSIS OF PENMAN EVAPORATION METHOD
}

\author{
MAMASSIS N.* \\ PANAGOULIA D. \\ NOVKOVIC A.
}

\author{
Department of Water Resources and Environmental Engineering \\ School of Civil Engineering \\ National Technical University of Athens \\ Heroon Polytechneiou 5, GR 15780 Zographou, Greece
}

Received: 08/01/2014

Accepted: $14 / 05 / 2014$

*to whom all correspondence should be addressed:

Available online: 20/05/2014

e-mail: nikos@itia.ntua.gr

\section{ABSTRACT}

In this paper the influence of key meteorological variables in Penman evaporation method was explored. Monthly data over a 16-years period (1993-2008)were used from Thissio-Athens meteorological station. The climatic parameters of surface air temperature, relative humidity, wind speed and sunshine duration were varied in Penman method and the obtained results were compared. Moreover, the investigation of sunshine duration during winter months was thoroughly examined. An open source software (Hydrognomon) was used for this exploration. The analysis showed that: (a) the influence of the meteorological parameters to evaporation is almost linear, (b) the temperature has the greater influence to annual evaporation while the relative humidity, wind speed and sunshine duration follow, and (c) the relationship between sunshine duration and evaporation in a monthly scale is not constant. During the winter months the increase of sunshine duration leads to decrease of evaporation. The performed analysis could be used to quantify the impact of climatic change on evaporation, to determine the accuracy of predicted evaporation against that obtained from the meteorological instruments, and to investigate the alternative values of several meteorological variables in the case of limited data sets.

Keywords: Evaporation, Penman method, sunshine duration, solar radiation, terrestrial radiation

\section{Introduction}

Evaporation is a key variable controlling a wide range of issues in hydrology, agronomy, forestry and land resources planning, such as water balance computation, irrigation management, river flow forecasting, and ecosystem modeling. Among all the components of hydrological cycle, evaporation is perhaps the most difficult to be estimated due to the complex interactions prevailing in the soilvegetation-atmosphere system under well-watered or stressed water conditions.

There is a great number of methods for estimation of evaporation with a rich critique in numerous reviews (e.g. Singh, 1989; Morton, 1994; Winter et al., 1995; Tegos et al., 2013). The methods for determining evaporation can be categorized in empirical (e.g. Kohler et al., 1995), water budget (e.g. Guitjens, 1982), energy budget (e.g. Fritschen, 1966), mass transfer (e.g. Harbeck, 1962), and combination (e.g. Penman, 1948).

Sensitivity and variability analysis of Penman method parameters (variables) is a potential tool of system identification and design in hydrological analyses (Coleman and Decoursey, 1976). The value of sensitivity analysis consists on developing the model or predicting method best suited to the specific problem. For the Penman model, the variation of meteorological parameters, i.e. air temperature, 
relative humidity, wind speed and solar radiation, can aid to: (a) quantify the impact of climatic variations on evaporation, (b) estimate the accuracy of predicted evaporation compared with that obtained from the meteorological instruments, and (c) investigate the alternative values of meteorological variables in the case that there are not exist adequate data.

In this context, the importance of meteorological parameters to Penman evaporation method (Penman 1948 ) is explored through sensitivity analysis at monthly and annual time scale. For this method, the significance of sunshine duration to long wave and short wave radiation is thoroughly examined because the results of the sensitivity analysis, which are later presented, show that there are meteorological conditions (particularly during winter months) in which the increase of sunshine duration leads to the decrease of evaporation.

In abroad basis, the sensitivity of evaporation and evapotranspiration models to physical and meteorological parametershas been examined by several authors for various climatic types and different spatial and temporal scales.These studies mainly focused on: (a) physical characteristics of the evapotranspiration surface (soil water content, height, plant density, canopy roughness, albedo) and (b) climatic parameters such as temperature, humidity, solar radiation, wind speed and thermodynamic characteristics of the atmosphere (e.g. Panagoulia, 1991, 1992a, 1992b).

Goyal (2004) studied the sensitivity of evapotranspiration in terms of change in temperature, solar radiation, wind speed and vapor pressure. He used meteorological data for a 32 years (1971-2002) period from the arid zone of Rajasthan, India. The parameters were varied within the range $+20 \%$ to $20 \%$ in their initial values. The results showed that the calculated evapotranspiration was most sensitive $(14.8 \%)$ to temperature, less sensitive to increase in net solar radiation $(11 \%)$ and wind speed $(7 \%)$.The increase in vapor pressure had a slightly negative effect on evapotranspiration (-4.31\%). Moreover,10\% increase in temperature and actual vapor pressure coupled with $10 \%$ decrease in net solar radiation resulted in marginal decrease of total evapotranspiration (0.3\%). Increase of $10 \%$ in temperature alone, or coupled with $10 \%$ decrease in net solar radiation, actual vapor pressure and wind velocity resulted in marginal decrease in total evapotranspiration (0.36\%).

Ambas (2010) as well as Ambas and Baltas (2012) proposed a sensitivity coefficient expressing the percentage change in evapotranspiration model that was caused from percentage change in meteorological variable or parameter through the use of standard deviation. This coefficient supports the advantage of revealing the model deviation caused by the usual change of variable or parameter and not the ability of each parameter to change the model.

Bakhtiari and Liaghat (2011) performed sensitivity analysis to the Penman-Monteith grass reference evapotranspiration. They examined the influence of mean air temperature, vapor pressure deficit, wind speed and short wave solar radiation in the semi-arid climate ofthe southeast Iran. Their results showed that the computed evapotranspiration was sensitive to vapor pressure deficit in all months, to wind speed from March to November, and to solar radiation during the summer months. Also the change in evapotranspiration was linearly related to the change in the climatic variables.

In the remainder of this paper, the study area and used data are described in the following Section 2. The influence of main climate parameters to Penman method is analyzed in Section 3 for monthly and annual scales. Subsequently, the sensitivity of sunshine duration to the Penman model in a seasonal scale is thoroughly examined (Section 4). Finally, the resulted conclusions are presented in Section 5.

\section{Study area and data}

The data used for the scope of the study were obtained from the Climatological Bulletins that are published by the Institute of Environmental Research and Sustainable Development of the National Observatory of Athens (NOA). The NOA meteorological station is situated at the top of Nymphs'Hill, in Thissioof Athens, Greece.The station is located atlatitude $37^{\circ} 58^{\prime} \mathrm{N}$, longitude $23^{\circ} 43^{\prime} \mathrm{E}$, and an altitude of 107 m.a.s.l. The Hill is covered by tall trees, but its surrounding region (city of Athens) is a densely populated area (urban area). Continuous records of standard meteorological parameters including surface air temperature $(T)$, wind speed $(W)$, relative humidity $(U)$, solar radiation $(D)$ and others have 
been carried out at this location since 1858. The station is considered as the most reliable meteorological station in Greece. Monthly data of surface air temperature, relative humidity, wind speed and sunshine duration for a 16-year period(1993-2008) were gathered from the mentioned station.

The statistical characteristics (mean values and variation coefficients) of mean monthly times series averaged over the 16-year period of the aforesaid parameters are presented in the Table 1.

Table 1 Statistical characteristics of average monthly time series for the four meteorological parameters over the 16-year period

\begin{tabular}{ccccccccc}
\hline & \multicolumn{2}{c}{$\mathrm{T}\left({ }^{\circ} \mathrm{C}\right)$} & \multicolumn{2}{c}{$\mathrm{U}(\%)$} & \multicolumn{2}{c}{$\mathrm{W}(\mathrm{m} / \mathrm{s})$} & \multicolumn{2}{c}{$\mathrm{D}(\mathrm{h})$} \\
\hline & Mean & $\mathrm{CV}$ & Mean & $\mathrm{CV}$ & Mean & $\mathrm{CV}$ & Mean & $\mathrm{CV}$ \\
\hline Jan & 9.8 & 0.16 & 73.9 & 0.04 & 3.3 & 0.20 & 143.4 & 0.23 \\
\hline Feb & 9.9 & 0.17 & 70.7 & 0.07 & 3.6 & 0.15 & 153.4 & 0.21 \\
\hline Mar & 12.2 & 0.15 & 66.9 & 0.07 & 3.7 & 0.18 & 204.2 & 0.19 \\
\hline Apr & 15.8 & 0.08 & 62.2 & 0.07 & 3.1 & 0.14 & 233.7 & 0.11 \\
\hline Mai & 21.4 & 0.04 & 56.5 & 0.10 & 3.2 & 0.14 & 305.7 & 0.10 \\
\hline Jun & 26.4 & 0.04 & 49.8 & 0.14 & 3.5 & 0.17 & 362.3 & 0.05 \\
\hline Jul & 28.9 & 0.04 & 47.9 & 0.14 & 3.8 & 0.19 & 384.0 & 0.04 \\
\hline Aug & 28.6 & 0.04 & 49.7 & 0.15 & 3.6 & 0.11 & 358.9 & 0.05 \\
\hline Sep & 24.1 & 0.05 & 59.2 & 0.13 & 3.2 & 0.17 & 278.1 & 0.10 \\
\hline Okt & 19.5 & 0.08 & 67.1 & 0.09 & 3.1 & 0.20 & 220.7 & 0.15 \\
\hline Noe & 14.6 & 0.10 & 73.7 & 0.04 & 3.2 & 0.19 & 144.4 & 0.21 \\
\hline Dek & 11.2 & 0.12 & 75.7 & 0.04 & 3.4 & 0.16 & 116.2 & 0.23 \\
\hline Year & 18.5 & 0.07 & 62.8 & 0.05 & 3.4 & 0.08 & 2905.0 & 0.04 \\
\hline
\end{tabular}

\section{Sensitivity analysis}

In order to calculate the evaporation, measurements of various physical parameters are needed (Koutsoyiannis and Xanthopoulos 1999; Panagoulia and Dimou 2000). Data from average monthly values of surface air temperature $\left(T,{ }^{\circ} \mathrm{C}\right)$, relative humidity $(\mathrm{U}, \%)$, sunshine duration $(\mathrm{D}, \mathrm{hr})$ and wind speed $(\mathrm{u}, \mathrm{m} / \mathrm{s})$ over the 16-year period (1993-2008) were used as inputs to Penman model (1948) as this is described in Hydrognomonopen source software package. Hydrognomon is a processing tool for evaporation calculation and this is widely used in Greece for management and analysis of hydrometeorological data (Kozanis et al., 2005).

The sensitivity analysis of Penman model was performed by changing (varying) the values of parameters (temperature, relative humidity, wind speed and sunshine duration) that are involved in the evaporation calculation. More specifically, the influence of each parameter to Penman model was examined by increasing and decreasing by $10 \%$ of its initial values, while the values of other parameters were held constant. In turn, the effect of variation to Penman model was quantified by using the equation (1) on monthly and annual scale. This analysis was repeated for each of the four parameters included in Penman model.

$\Delta \mathrm{ET}=\frac{\mathrm{ET}_{\mathrm{v}}-\mathrm{ET}_{0}}{\mathrm{ET}_{0}} \times 100$

Where, $\triangle E T$ is the relative difference of evaporation (\%), $E T_{v}$ is the evaporation calculated with varied parameters, and $\mathrm{ET}_{0}$ is the evaporation with initial parameters.

Subsequently, by applying the equation (1), the mean and standard deviation values were calculated for the monthly evaporation differences (\%) for $10 \%$ of both increase and decrease in each of the four parameters. The resulted percentages differences of evaporation in mean monthly values are presented in Figure 1. 

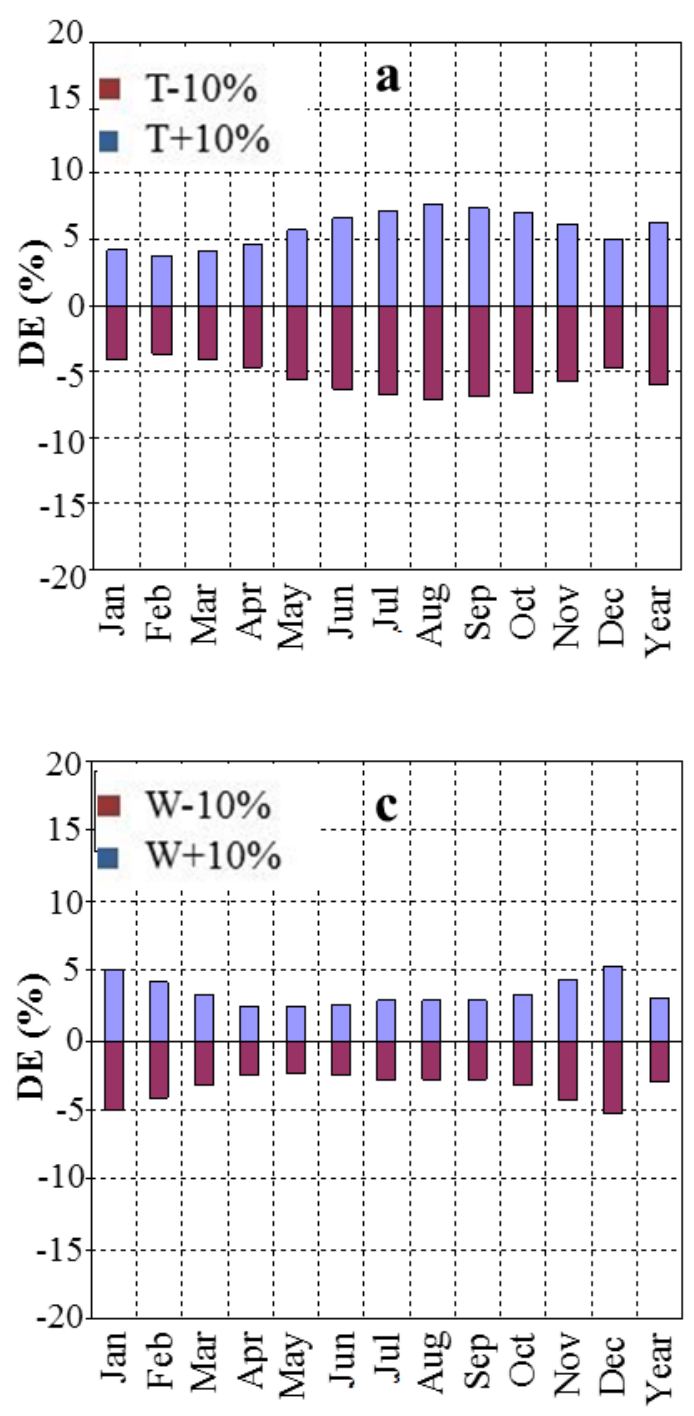
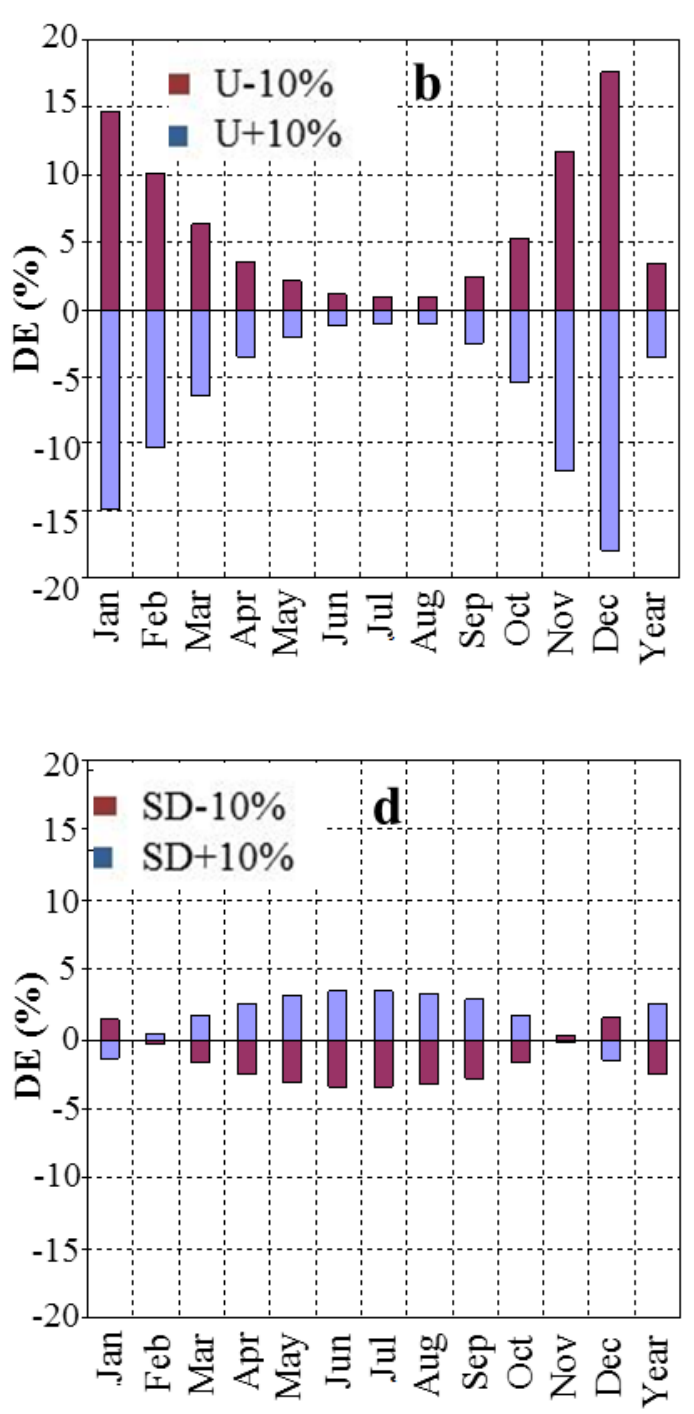

Figure 1. Mean monthly values for evaporation difference (\%) for $10 \%$ increase and $10 \%$ decrease of (a) temperature, (b) relative humidity, (c) wind speed and (d) sunshine duration

From the evaporation values of Figure 1 it is clear that: (a) the influence of each parameter to monthly and annual evaporation is almost linear and (b) the temperature presents the greater influence in the annual evaporation ( $6 \%$ for $10 \%$ alteration), followed by the relative humidity (-3.5\% for $10 \%$ alteration), wind speed ( $3 \%$ for $10 \%$ alteration) and sunshine duration ( $2.6 \%$ for $10 \%$ alteration). Moreover, the temperature influence in monthly evaporation during summer months is greater than that of winter months in which the relative humidity greatly influences the monthly evaporation. Even, the influence of temperature and sunshine duration in evaporation in summer months is greater than that in winter months. This is contrasted to the influence of relative humidity and wind speed that is greater during winter months than that in summer months.

Furthermore, the values and graphs analysis revealed that the relationship between sunshine duration and monthly evaporation is not constant. Although in the general sense, the increase of sunshine duration leads to the increase of evaporation, in some winter months the opposite occurs. This finding led us to further analysis of sunshine duration parameter that is extensively investigated in a next section.

Another issue that characterizes the performance of the evaporation method is the variance or standard deviation. Figure 2 reflects this aspect via the alterations in temperature, relative humidity, wind speed and sunshine duration. 

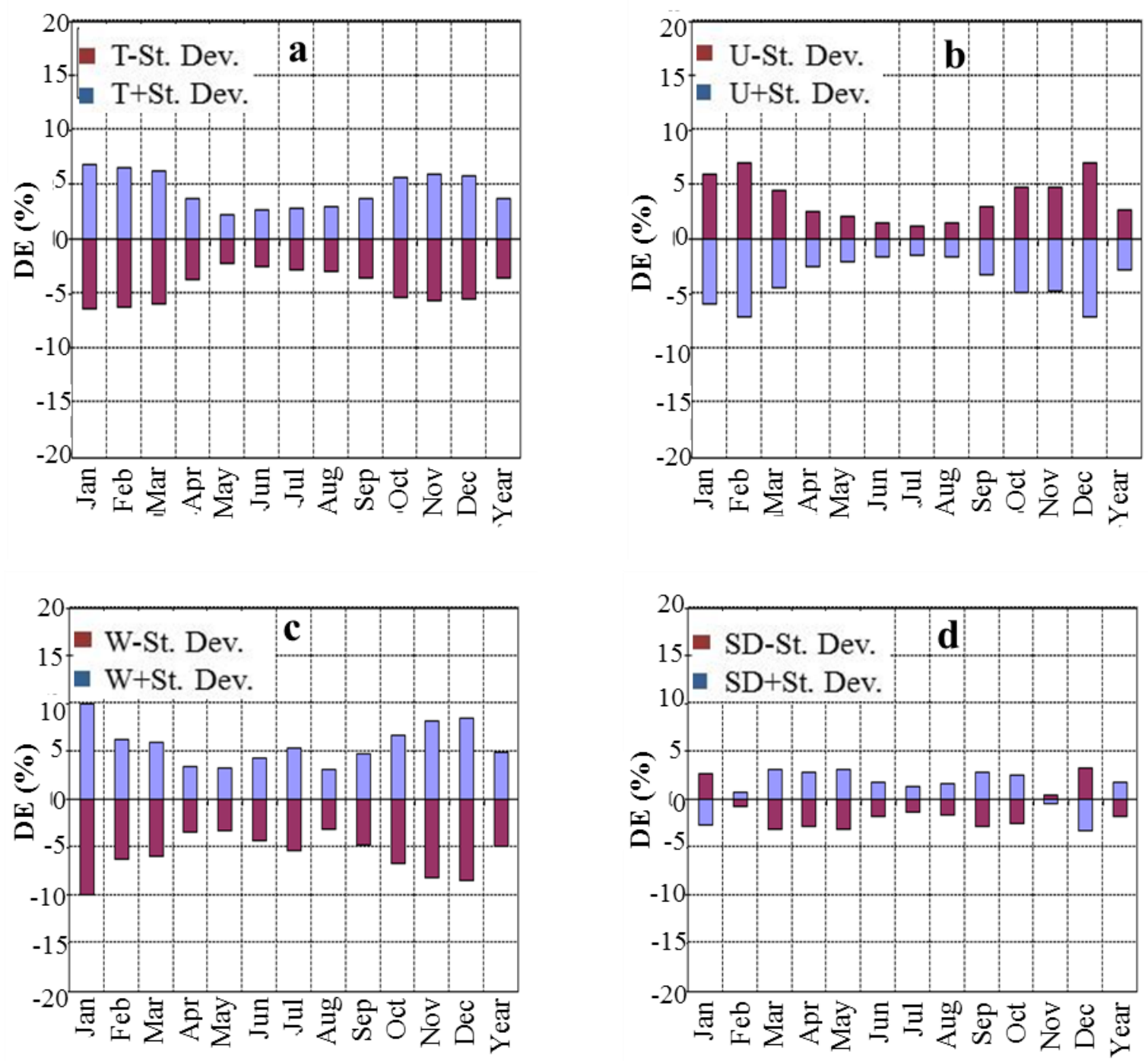

Figure 2. Mean monthly evaporation values difference (\%) for a standard deviation increase and decrease of (a) temperature, (b) relative humidity, (c) wind speed and (d) sunshine duration.

In Figure 2 the large variances of monthly values of wind speed produce great influence in annual evaporation ( $5 \%$ for standard deviation alteration) and monthly evaporation during summer and winter months. The influence of temperature remains large in annual and monthly scale, but that of relative humidity decreases due to the small values of monthly variances.

\section{Sensitivity analysis of sunshine duration}

Because the current research revealed that the increase of sunshine duration can lead to less evaporation (and vice versa) in some months, this finding was more thoroughly explored by investigating the factor of the net radiation on land surface $\left(R_{n}\right)$ that is dependent on relative sunshine (duration of observed sunshine to potential sunshine). According to Penman method, $R_{n}$ is defined as the difference between net shortwave radiation $\left(S_{n}\right)$ and net longwave radiation $\left(L_{n}\right)$. The importance of $\mathrm{S}_{\mathrm{n}}$ to several natural processes and human activities, as well as its distribution on the Earth's surface has been examined by Mamassis et al. (2012).

Using the Penman equation, the net shortwave and net long wave solar radiations are estimated as follows.

The net shortwave solar radiation, $S_{n}$ is given by the equation: 
$S_{n}=(1-\alpha) f_{s} S_{0}$

where, $\alpha$ is the albedo coefficient, $S_{0}$ the extraterrestrial solar radiation in $\mathrm{kJ} / \mathrm{m}^{2} / \mathrm{d}$, and $\mathrm{f}_{\mathrm{s}}$ the absorption (Prescott) coefficient of the atmosphere.

The absorption coefficient $f_{s}$ is described by the equation:

$$
f_{S}=\alpha_{S}+b_{S} \frac{n}{N}
$$

where, $\alpha_{s}, b_{s}$ are the Prescott coefficients with default values $a_{s}=0.25$ and $b_{s}=0.50$, and $n / N$ is the relative sunshine.

The net longwave radiation, $L_{n}$, is determined by the equation:

$L_{n}=\varepsilon_{n} f_{L} \sigma(T \alpha+273)^{4}$

where, $\sigma$ is the Stefan-Boltzmann constant with value $4.9 \times 10^{-6} \mathrm{~kJ} /\left(\mathrm{m}^{2} \mathrm{~K}^{4} \mathrm{~d}\right), \mathrm{T}_{\alpha}$ the average temperature $\left({ }^{\circ} \mathrm{C}\right), \mathrm{f}_{\mathrm{L}}$ the cloud rate effect, and $\varepsilon_{\mathrm{n}}$ the net emission capacity

The cloud rate effect $f_{L}$ is provided from the equation:

$f_{L}=\alpha_{L}+b_{L} \frac{n}{N}$

where, $a_{L}$ and $b_{L}$ are constants with default values $a_{L}=0.1$ and $b_{L}=0.9$.

The net emission capacity $\varepsilon_{\mathrm{n}}$ is estimated via the equation:

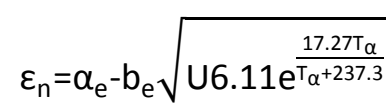

where, $a_{e}$ and $b_{e}$ are the coefficients with default values $a_{e}=0.56$ and $b_{e}=0.08$, and $U$ is the relative humidity (\%).

The values of $R_{n}, S_{n}$ and $L_{n}\left(\right.$ in $\mathrm{kJ} / \mathrm{m}^{2} /$ d) for different values of relative sunshine $(n / N)$ and for the four months (January, April, July and October) were calculated by using the equations (2) and (4). The variability of the net longwave radiation $\left(L_{n}\right)$ and net shortwave (solar) radiation $\left(S_{n}\right)$ for various values of relative sunshine $(\mathrm{n} / \mathrm{N})$ is reflected in Figure 3.

For the calculation of $L_{n}$ the mean tested values of temperature and relative humidity in each month were used. For the calculation of $S_{n}$ an albedo with value of 0.08 (typical for water) was considered. Both the latitude of the meteorological station $\left(37^{\circ} 58^{\prime} \mathrm{N}\right)$ and the specific month were considered for defining the extraterrestrial solar radiation $\mathrm{S}_{0}$.

From Figure 3 , it is obvious that the slope of $S_{n}$ is strongly dependent on the month of the year presenting its higher value during July and lower value during January. The slope of $L_{n}$ is less dependent on month but it slightly increases during winter months (January and October). In January, the slope of $L_{n}$ is greater than the slope of $S_{n}$, leading to the decrease of $R_{n}$ as relative sunshine increases. This fact indicates that evaporation decreases as relative sunshine increases. 

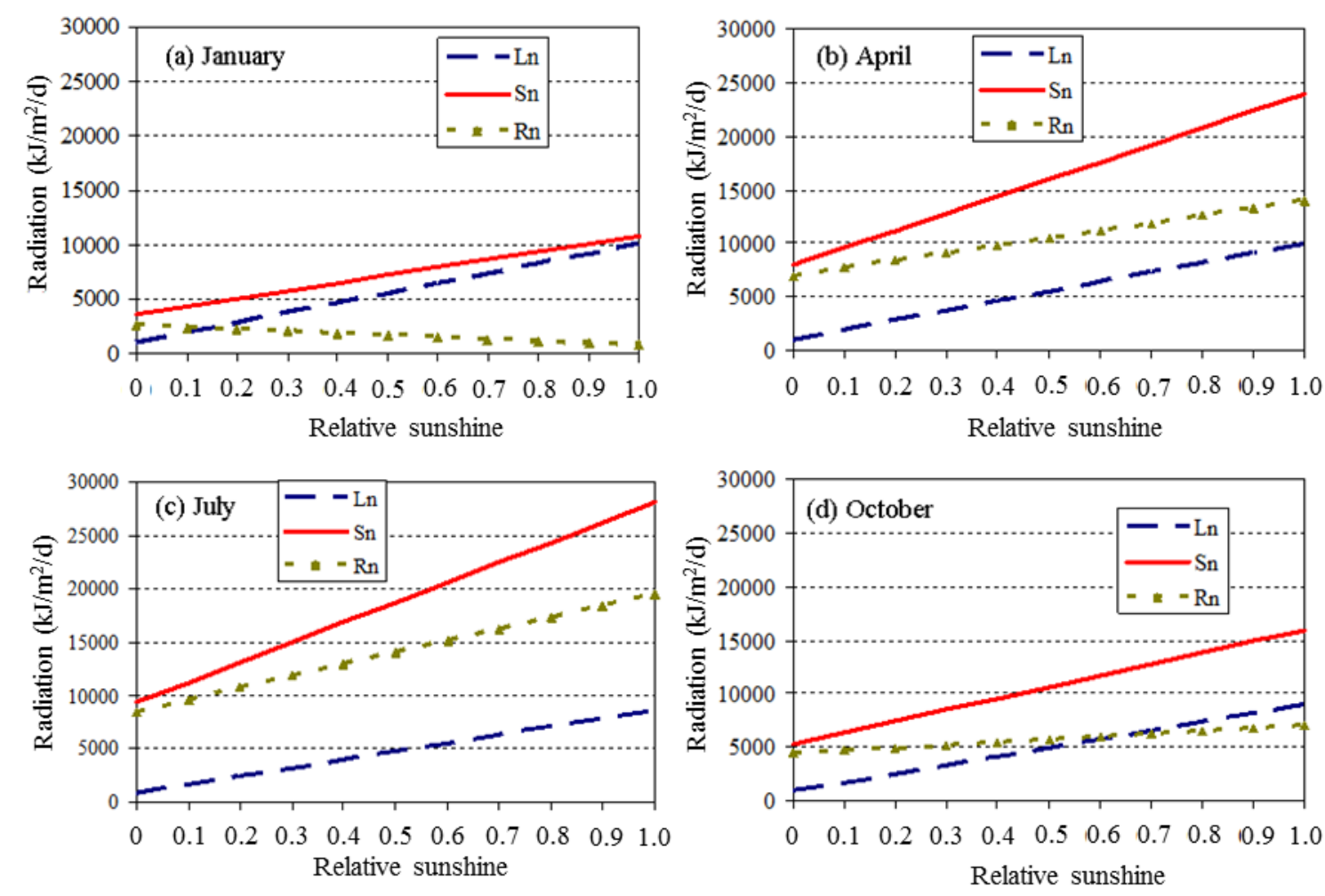

Figure 3 Variability of net longwave radiation $\left(L_{n}\right)$ and net shortwave (solar) radiation $\left(S_{n}\right)$ along the values of relative sunshine $(n / N)$ for the four months characterized from the discussed phenomenon

For further ensuring of the aforementioned finding the discussed phenomenon was investigated for December and February. In graphical display the relative results are reflected in Figure 4.
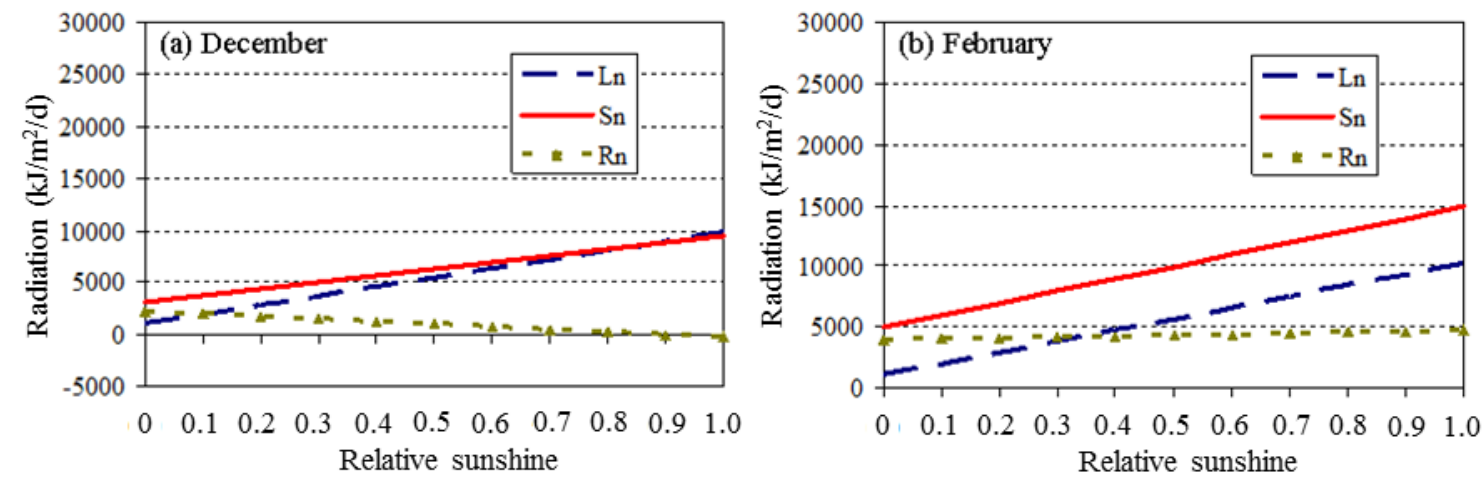

Figure 4 Variability of net longwave radiation $\left(L_{n}\right)$ and net shortwave (solar) radiation $\left(S_{n}\right)$ along the values of relative sunshine $(\mathrm{n} / \mathrm{N})$ for December and February

In December, the slope of $S_{n}$ remains smaller than that of $L_{n}$ highlighting that the increase of relative sunshine can lead to the decrease of the net radiation $R_{n}$. Also, in the case that the relative sunshine is 1 the net radiation $R_{n}$ is negative. In February, the slope of $S_{n}$ is almost equal to the slope of $L_{n}$ indicating that the net radiation $R_{n}$ is almost independent on the relative sunshine.

For a more thorough analysis in the evolution of $L_{n}$ along the relative sunshine, the evolution under the influence of various values in temperature and relative humidity was examined (Figure 5). 


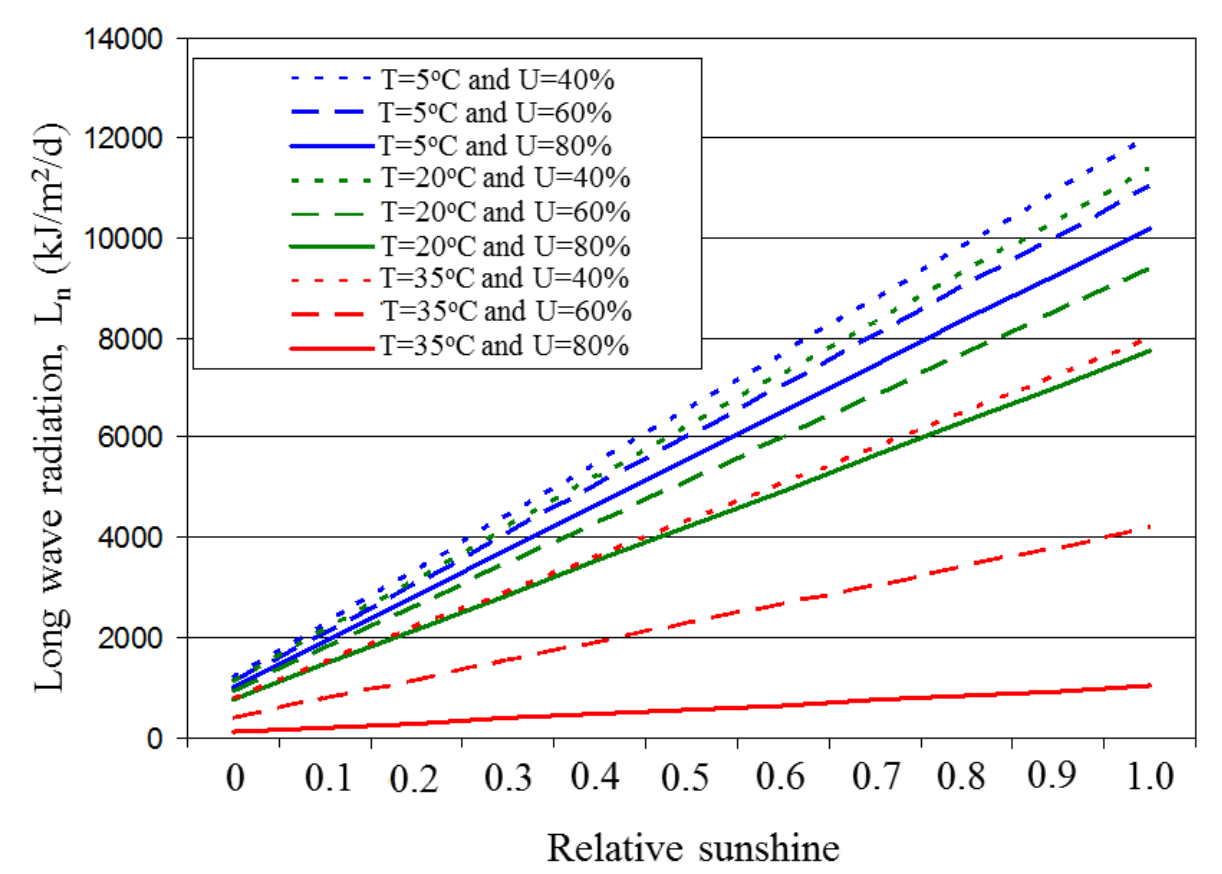

Figure 5. Evolution of $L_{n}$ along the relative sunshine $(n / N)$ for various values of temperature and relative humidity

From Figure 5 , it is obvious that the slope of $L_{n}$ is strongly dependent on temperature and relative humidity. As temperature and relative humidity decrease the slope of $L_{n}$ increases.

In order to quantify the influence of the relative sunshine to the value of $R_{n,}$, that is defined as an abstraction of $L_{n}$ from $S_{n,}$, the derivatives of these two variables to the relative sunshine were calculated. Using equations (2) and ( 3 ) the $S_{n}$ is calculated as:

$S_{n}=(1-\alpha) S_{0}\left(\alpha_{S}+b_{S} \frac{n}{N}\right)$

Using equations (4) and (5) the $L_{n}$ is calculated as:

$L_{n}=\varepsilon_{n L} \sigma\left(T_{\alpha}+273\right)^{4}\left(\alpha_{L}+b_{L} \frac{n}{N}\right)$

The derivatives of equations (7) and (8) to relative sunshine give:

$\frac{\partial S_{n}}{\partial\left(\frac{n}{N}\right)}=(1-\alpha) S_{0} b_{S}$

$\frac{\partial L_{n}}{\partial\left(\frac{n}{N}\right)}=b_{L} \varepsilon_{n L} \sigma\left(T_{\alpha}+273\right)^{4}$

Using the equation (6), the equation (10) can be written as

$\frac{\partial L_{n}}{\partial\left(\frac{n}{N}\right)}=\left(\alpha_{e}-b_{e} \sqrt{U 6.11 e^{\frac{17.27 T_{\alpha}}{T_{\alpha}+237.3}}}\right) b_{L} \sigma\left(T_{\alpha}+273\right)^{4}$

From Equations (9) and (11) the derivative of $R_{n}$ to relative sunshine is given by:

$\frac{\partial R_{n}}{\partial\left(\frac{n}{N}\right)}=\frac{\partial S_{n}}{\partial\left(\frac{n}{N}\right)}-\frac{\partial L_{n}}{\partial\left(\frac{n}{N}\right)}=(1-\alpha) S_{0} b_{S^{-}}\left(\alpha_{e}-b_{e} \sqrt{U 6.11 e^{\frac{17.27 T_{\alpha}}{T_{\alpha}+237.3}}}\right) b_{L} \sigma\left(T_{\alpha}+273\right)^{4}$ 
From equation (9) the value of the derivative $S_{n}$ to $n / N$ is dependent on $S_{o}$ and albedo coefficient. The values of the derivative $S_{n}$ to $n / N$ for different values of albedo are presented in Table 2 .

Table 2 Influence of albedo coefficient to the derivative $S_{n}$ to $n / N$

\begin{tabular}{cccc}
\hline So & $\Theta S_{n} / \theta(n / N) a=0.04$ & $\Theta S_{n} / \theta(n / N) a=0.08$ & $\theta S_{n} / \theta(n / N) a=0.25$ \\
\hline 10000 & 4800 & 4600 & 3750 \\
\hline 15000 & 7200 & 6900 & 5625 \\
\hline 20000 & 9600 & 9200 & 7500 \\
\hline 25000 & 12000 & 11500 & 9375 \\
\hline 30000 & 14400 & 13800 & 11250 \\
\hline 35000 & 16800 & 16100 & 13125 \\
\hline 40000 & 19200 & 18400 & 15000 \\
\hline 45000 & 21600 & 20700 & 16875 \\
\hline 50000 & 24000 & 23000 & 18750
\end{tabular}

The values of Table 2 indicate that the increase of albedo leads to the decrease of the derivative $S_{n}$ to $\mathrm{n} / \mathrm{N}$.

From equation (11) the derivative of $L_{n}$ to $n / N$ is dependent on temperature and relative humidity. This dependence is presented in Figure 6 where the derivatives of $L_{n}$ for the prevailed temperature and relative humidity of the four months (October, February, May and August) at Thissio station are plotted. Figure 6 clearly shows that the combination of low temperature with high relative humidity leads to higher values of the derivative of $L_{n}$.

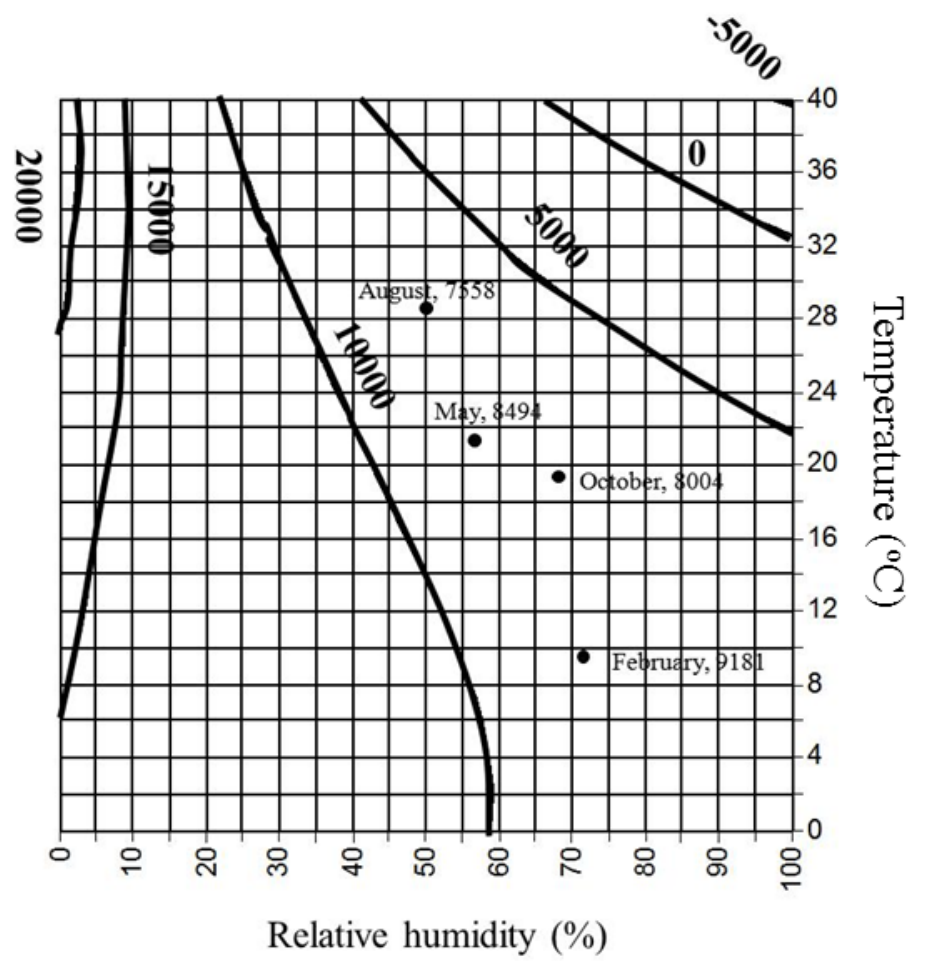

Figure 6 Derivative of $L_{n}$ for a range of values in temperature and relative humidity.

The temperature and relative humidity that lead to negative values of the equation (12) (increase of sunshine duration resulting to decrease of evaporation) are examined in Figure 7. 


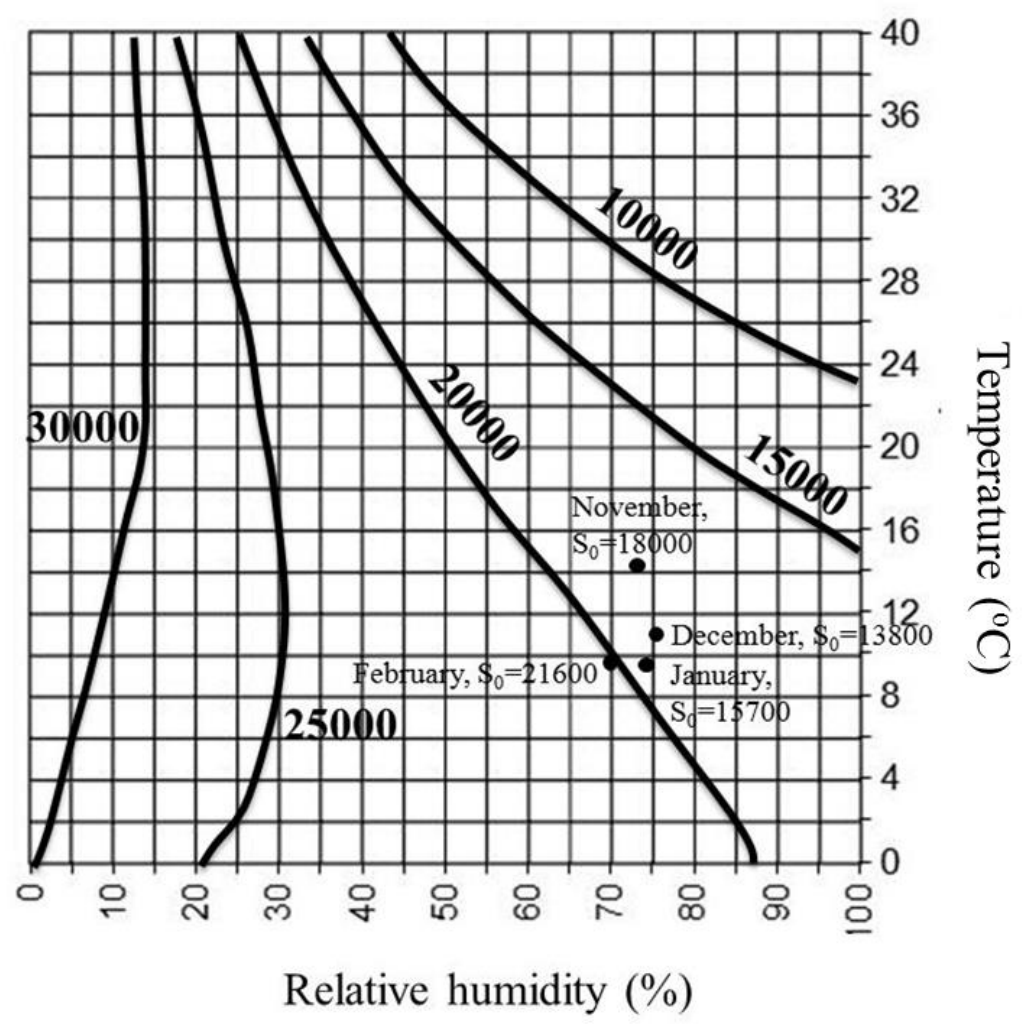

Figure 7 Combination of temperature and relative humidity for different $\mathrm{S}_{\mathrm{o}}$ levels that equation (12) takes negative values

Figure 7 shows that for each value of $\mathrm{S}_{0}$ the line separates the diagram in two regions. In the left region of the line, the combination of temperature and relative humidity leads to the conditions under which the derivative of $R_{n}$ is negative according to equation (12). Also, in the Figure 7 the meteorological parameters (temperature, humidity and extraterrestrial solar radiation) for the four winter months (November, December, January and February) are reflected.

The values of the derivatives $\theta \mathrm{S}_{\mathrm{n}}$ for the climatological parameters of the Thissio station for two different albedo values are presented in Table 3.

Table 3 Derivatives of $S_{n}$ and $L_{n}$ for mean climatological parameters of the Thissio station

\begin{tabular}{|c|c|c|c|c|c|c|c|c|}
\hline & $S_{0}$ & $\mathrm{~T}$ & U & $\begin{array}{c}\theta S_{n} \\
(a=0.08)\end{array}$ & $\begin{array}{c}\theta S_{n} \\
(a=0.25)\end{array}$ & $\theta I_{n}$ & D1 & D2 \\
\hline Jan & 15700 & 9.8 & 73.9 & 7222 & 5888 & 9043 & -1821 & -3155 \\
\hline Feb & 21600 & 9.9 & 70.7 & 9936 & 8100 & 9181 & 755 & -1081 \\
\hline Mar & 27600 & 12.2 & 66.9 & 12696 & 10350 & 9141 & 3555 & 1209 \\
\hline Apr & 34700 & 15.8 & 62.2 & 15962 & 13013 & 8978 & 6984 & 4035 \\
\hline Mai & 39600 & 21.4 & 56.5 & 18216 & 14850 & 8494 & 9722 & 6356 \\
\hline Jun & 41700 & 26.4 & 49.8 & 19182 & 15638 & 8107 & 11075 & 7531 \\
\hline Jul & 40700 & 28.9 & 47.9 & 18722 & 15263 & 7714 & 11008 & 7549 \\
\hline Aug & 36800 & 28.6 & 49.7 & 16928 & 13800 & 7558 & 9370 & 6242 \\
\hline Sep & 30400 & 24.1 & 59.2 & 13984 & 11400 & 7653 & 6331 & 3747 \\
\hline Okt & 23100 & 19.5 & 67.1 & 10626 & 8663 & 8004 & 2622 & 658 \\
\hline Noe & 18000 & 14.6 & 73.7 & 8280 & 6750 & 8448 & -168 & -1698 \\
\hline Dec & 13800 & 11.2 & 75.7 & 6348 & 5175 & 8806 & -2458 & -3631 \\
\hline
\end{tabular}

Columns D1 and D2 contain the differences of the two derivatives for the two albedo values. The negative values of differences in D1 and D2 columns of Table 3 show that the derivative of $R_{n}$ to 
sunshine duration is negative. This finding indicates that the values of the climatic characteristics of Athens in winter months can lead to a climatologic phenomenon interpreted by evaporation decrease under sunshine duration increase.

This effect would be weakened if the Prescott coefficients $\left(a_{s}, b_{s}\right.$; Equation 7$)$ are differentiated from their default values. The analysis showed that an increase more than $30 \%$ in the initial values could influence the examined effect. In this case, the modification of Prescott coefficients would lead to an overestimation of the calculated evaporation.

\section{Conclusions}

In this paper a sensitivity analysis to Penman evaporation for various meteorological parameters was investigated. Also, the relationship between sunshine duration and monthly evaporation was thoroughly explored. Many researchers have studied the sensitivity analysis of key meteorological parameters in evaporation or evapotranspiration methods. However, the present study offered new findings to the theme analysis, in some cases confirming the findings of other authors and in others giving new insights. The linear influence of the meteorological parameters to evaporation is almost known, but here this has been proved by Penman evaporation method in an forestry environment surrounded by a densely populated area (the city of Athens, Greece).The entirely new finding that more sunshine can lead to less evaporation may be attributed to the particular meteorological conditions which prevail around the recording station.

From the overall research study the following conclusions could be drawn:

1. The influence of the key meteorological parameters to monthly and annual evaporation is almost linear.

2. The temperature has the greater influence to annual evaporation while the relative humidity, wind speed and sunshine duration follow. During summer months the temperature has the greater influence to monthly evaporation while the relative humidity greatly influences the evaporation during the winter months.

3. The influence of temperature and sunshine duration in evaporation is greater during the summer months, than that in winter months. The opposite occurs with the influence of relative humidity and wind speed

4. The relationship between sunshine duration and monthly evaporation is not constant. Although in the general sense the increase of sunshine duration leads to increase of evaporation, in the explored region, the opposite occurs in some winter months.

\section{References}

Ampas V. (2010), Research and estimation of meteorological parameters with direct impact on agriculture, Ph.D. Thesis. Aristotle Un. Th.

Ampas V. and E. Baltas (2012), Sensitivity analysis of different evapotranspiration methods with a new sensitivity coefficient, Global NEST Journal, 14(3), 335-343.

Bakhtiari B. and A.M. Liaghat (2011), Seasonal Sensitivity Analysis for Climatic Variables of ASCE Penman-Monteith Model in a Semi-arid Climate, J. Agr. Sci. Tech., 13, 1135-1145.

Coleman G. and DeCoursey D.G. (1976), Sensitivity and model variance analysis applied to some evaporation and evapotranspiration models, Water Resources Research, 12(5), 873-879, doi:10.1029/WR012i005p00873.

Fritschen L.J. (1966), "Energy balance method", Proceedings, American Society of Agricultural Engineers Conference on Evapotranspiration and its role in Water Resources Management, December 5 56 , Chicago, IL. St. Joseph, MI. pp. 34-37.

Goyal R.K. (2004), Sensitivity of evapotranspiration to global warming: a case study of arid zone of Rajasthan (India), Agricultural Water Management, 69(1), 1-11, doi:10.1016/j.agwat.2004.03.014.

Guitjens J.C. (1982), "Models of alfalfa yield and evapotranspiration", J. Irrig. Drain. Div. Proc. Am. Soc. Civ. Eng., 108(IR3), 212-222. 
Harbeck G.E. (1962), "A practical field technique for measuring reservoir evaporation utilizing mass-transfer theory", Geological Survey Professional Paper 272-E. US Government Printing Office, Washington, D.C, pp. 101-105.

Kohler M.A., Nordenson T.J. and Fox W.E. (1955), "Evaporation from pans and lakes", Weather Bureau Research Paper 38.US Department of Commerce, Washington, D.C.

Koutsoyiannis D. and Xanthopoulos Th. (1999), Engineering Hydrology, Edition 3, Chapter 3 Evaporation and transpiration. National Technical University of Athens (in Greek).

Kozanis S., Hristofidis A. and Evstratiadis A. (2005), Description of data management and processing in "Hydrognomon" Issue 2. Integrated Management of Hydrosystems in Conjunction with an Advanced Information System ODYSSEUS (in Greek).

Mamassis N., Efstratiadis A. and Apostolidou E. (2012), Topography-adjusted solar radiation indices and their importance in hydrology, Hydrological Sciences Journal, 57(4), 756-775.

Morton F.I. (1994), Evaporation research - A critical review and its lessons for the environmental sciences, Crit. Rev. Environ. Sci. Tech., 24(3), 237-280.

Panagoulia and Dimou (2000), Introduction to land reclamation works, Edition 2, Chapter 2 Crops and Irrigation. Teaching Book. National Technical University of Athens (in Greek).

Panagoulia D. (1991), Hydrological response of a medium-sized mountainous catchment to climate changes, Hydrological Sciences Journal, 36(6), 525-547.

Panagoulia D. (1992a), Hydrological modelling of a medium-size mountainous catchment from incomplete meteorological data, Journal of Hydrology, 137(1-4), 279-310.

Panagoulia D. (1992b), Impacts of GISS-modelled climate changes on catchment hydrology, Hydrological Sciences Journal, 37(2), 141-163.

Penman H.L. (1948), Natural evaporation from open water, bare soil and grass Proceedings of the Royal Society of London. Series A, Mathematical and Physical Sciences, 193(1032), 120-145.

Piper B.S. (1989), Sensitivity of Penman estimates of evaporation to errors in input data, Agricultural Water Management, 15(3), 279-300, doi:10.1016/0378-3774(89)90021-8.

Singh V.P. (1989), Hydrologic Systems, Vol. II, Watershed Modelling. Prentice-Hall, Inc.

Tegos A., Efstratiadis A. and Koutsoyiannis D. (2013), A parametric model for potential evapotranspiration estimation based on a simplified formulation of the Penman-Monteith equation, Evapotranspiration - An Overview, edited by S. Alexandris, 143-165, doi:10.5772/52927.

Winter T.C., Rosenberry D.O. and Sturrock A.M. (1995), Evaluation of 11 equations for determining evaporation for a small lake in the north central United States, Wat. Resour. Res., 31(4), 983-993. 